\title{
Vocalizing during gaps in anthropogenic noise is an uncommon trait for enhancing communication in songbirds
}

Original paper

Article history:

Received: 21 July 2017

Accepted: 17 September 2017

Published: 26 October 2017

Check for updates

*Correspondence:

DSP: dsp5@calvin.edu

Peer review:

Double blind

\section{Copyright:}

(C) 2017 Proppe and Finch. (- This is an open access article distributed under the Creative Commons Attribution License (CC-BY 4.0), which permits unrestricted use, distribution, and reproduction in any medium, provided the original work is properly cited and its authors credited.

\section{Keywords:}

noise; bird; temporal shift; frequency; sound window; gap; behavior

\section{Citation:}

Proppe D. S. and Finch E. (2017). Vocalizing during gaps in anthropogenic noise is an uncommon trait for enhancing communication in songbirds. Journal of Ecoacoustics. 1: \#TLP16D.

https://doi.org/10.22261/JEA.TLP16D
Darren S. Proppe ${ }^{1, *}$, Emily Finch $^{1}$

${ }^{1}$ Calvin College, 3201 Burton St SE, 49546 Grand Rapids, United States

\begin{abstract}
Mounting evidence suggests that anthropogenic noise negatively impacts many wildlife species, including songbirds. One mechanism by which noise affects songbirds may be through acoustic obstruction to their systems of vocal communication. However, many species increase the amplitude or pitch of their vocalizations, which may partially mitigate the impact of high noise levels. When the amplitude of anthropogenic noise varies over time, such as near a moderate-use highway, short gaps between noise events may also provide an important opportunity for communication. But, whether songbirds adjust vocalization rates rapidly to avoid overlap with noise is unknown for most species. We used acoustic playback to expose songbirds to simulated road noise during the dawn chorus in otherwise quiet habitats. We measured vocalization rates under ambient conditions and during quiet gaps embedded within playback of road noise to assess whether a community of songbirds, and nineteen individual species, vocalize more regularly during noise gaps. There were no significant differences in community-wide acoustic output. Species-specific analysis revealed that only four species altered their vocal rates during quiet gaps in noise, but that the direction of the effect varied by species. Point count results revealed that birds generally remained on site for the duration of the experiment, suggesting that abandonment of noisy locations was unlikely to confound our results. In sum, increasing vocal output during short gaps in noise occurred in only a handful of species, perhaps contributing to the limited number of species that are found within noisy habitats.
\end{abstract}

As human development increases, anthropogenic noise is altering the soundscape in much of the biosphere. According to Mennitt et al. (2013) the majority of the landmass in the United States is already impacted by anthropogenic noise. The spread of anthropogenic noise is not without consequences for wildlife; in some cases contributing to reduced abundance and diversity (McClure et al., 2013; Francis and Barber, 2013), lower density (Bayne et al., 2008), reduced reproductive success (Halfwerk et al., 2011), and altered age 
distribution and mating systems (Reijnen and Foppen, 1995; Swaddle and Page, 2007). Songbirds are particularly vulnerable to noise, likely because they rely on acoustic forms of communication that are compromised by external noise (Slabbekoorn and Ripmeester, 2008). Yet, some birds possess traits that facilitate communication in noisy areas. Vocalizing at or shifting to higher pitches and amplitudes appears to reduce the impacts of lower-frequency anthropogenic noise on some species (Rheindt, 2003; Slabbekoorn and Peet, 2003; Brumm, 2004; Hu and Cardoso, 2009). Pitch and amplitude changes may increase the likelihood that the signal is perceived by the intended receiver, however, both mechanisms may become less useful as noise levels increase (Nemeth and Brumm, 2010). Even at high amplitudes, noise production often varies temporally near most noise producing sources, such as roads (Kerner and Rehborn, 1996). Birds can potentially continue to communicate during low noise periods such as between car passes. As such, temporal adjustment may be a valuable and underexplored mechanism for communicating in noisy areas, but only if songbirds alter the timing of their vocalization rates accordingly.

Many species, including birds (Brumm, 2006; Fitzsimmons et al., 2008; Hart et al., 2015), frogs (Schwartz and Bee, 2013), insects (Greenfield, 1994), and mammals (Schneider et al., 2008), adjust the timing of their songs to avoid overlap with acoustic signals produced by conspecifics and heterospecifics. In many cases, aversion to overlap may be related to dominance hierarchies and behavioral state (Naguib and Mennill, 2010), but release from acoustic masking may also be important. Recent studies show that European robins (Erithacus rubecula), spotless starlings (Sturnus unicolor), and house sparrows (Passer domesticus) that inhabited noisy urban areas began vocalizing earlier in the day than their counterparts that inhabited quiet locations, potentially due to lower traffic intensities before dawn (Fuller et al., 2007; Arroyo-Sollis et al., 2013). Reed buntings (Emberiza schoeniclus) in roadside habitats exhibited higher singing rates on days when traffic levels were low (Gross et al., 2010). Conversely, Yang and Slabbekoorn (2014) found that Eurasian wrens (Troglodytes troglodytes) did not exhibit differential vocal rates between quiet and noisy locations, and did not alter singing rates during brief playbacks $(20 \mathrm{~s})$ of anthropogenic noise. Theoretically, concentrating vocal production during quieter periods embedded within high levels of anthropogenic noise could conserve energy and facilitate communication (Slabbekoorn and Ripmeester, 2008). But the extent to which songbirds employ this vocal pattern in response to noise is less known, especially over short time scales (e.g., seconds or minutes).

We investigated whether 19 songbird species altered their vocalization patterns during quiet gaps embedded within short-term exposure to anthropogenic noise. Our exposure consisted of three consecutive mornings, designed to mimic the situation a bird may encounter at stopover habitats during migration, or on their breeding grounds as a result of temporary anthropogenic activities such as road and well maintenance or nearby logging activity. To avoid confounds associated with using roads and urban habitats, we played back simulated road noise in otherwise quiet habitats. We predicted that birds would increase vocalization rates during quiet gaps embedding within playback of anthropogenic noise because of the theoretical communication benefits.

\section{Methods}

\section{Site selection}

Research was conducted from 22 May 2013-4 July 2013, on the premises of the Pierce Cedar Creek Institute near Hastings, Michigan, USA $\left(42.5358^{\circ} \mathrm{N}, 85.3014^{\circ} \mathrm{W}\right.$; Figure 1$)$. The property was ideal for our experimental approach because low levels $(<40 \mathrm{dBA}$, re $20 \mu \mathrm{Pa})$ of ambient noise allowed for a high degree of control over the noise present during each experiment. Twelve sites were utilized to compare vocal production under control conditions and under experimentally elevated noise conditions. Each site was located entirely within mesic hardwood forests dominated by a mature maplebeech canopy typical of the region. Sites were separated by at least $350 \mathrm{~m}$ to reduce the likelihood of psuedoreplication. 


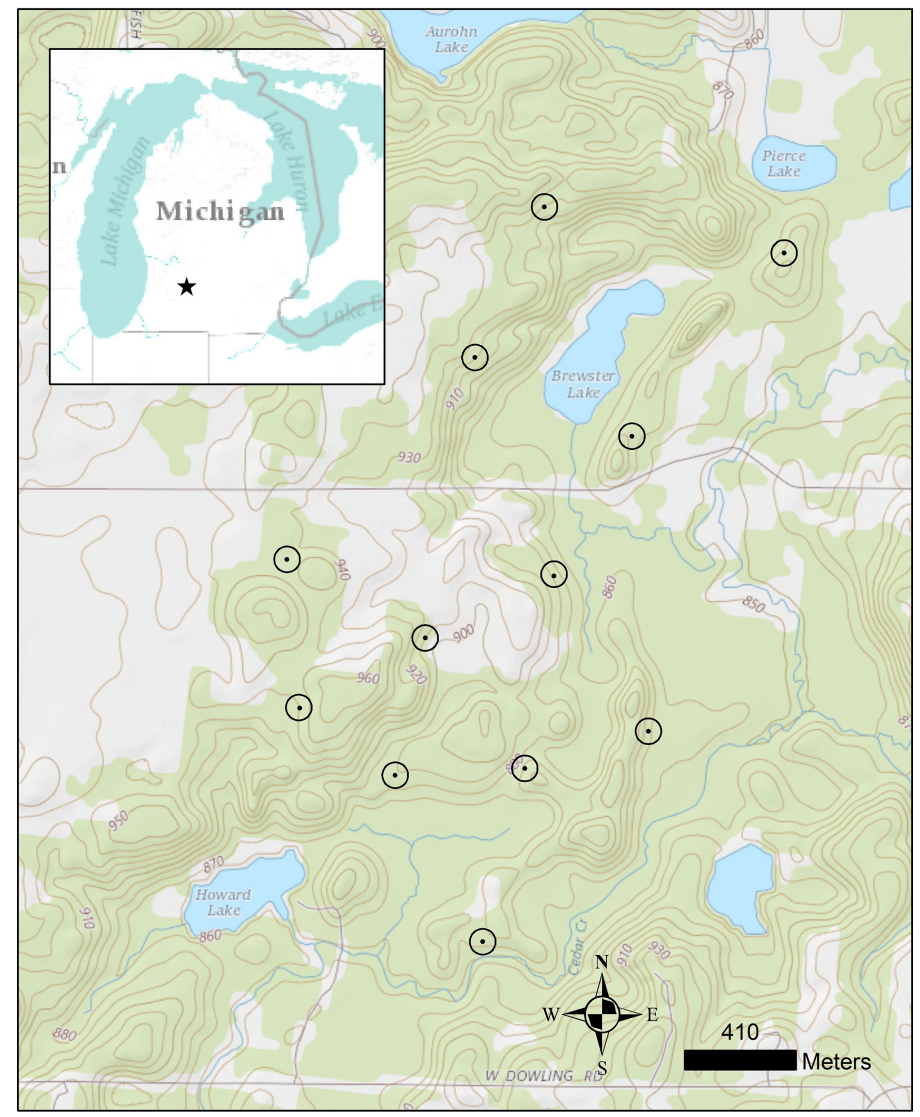

Figure 1. Map of playback locations at the Pierce Cedar Creek Institute in Southwestern Michigan (indicated by the star on the inset map).

Shaded areas indicate maple-beech deciduous forest cover. Recording devices were placed at the center point in each site and the circular buffer indicates the area impacted by noise playback (35 $\mathrm{m}$ radius).

\section{Vocal recording and noise playback}

Songbird vocalizations were recorded for five days during each treatment. Two experimental and two control treatments were run simultaneously each week to control for seasonal variation in vocalization rates. Nineteen songbird species were selected for study based on their known prevalence in forest and forest edge habitats during surveys conducted in 2011 and 2012 at Pierce Cedar Creek (Table 1, R. Keys personal communication). Each site consisted of a circular $35 \mathrm{~m}$ radius recording area centered on a passive recording device (SM1: Wildlife Acoustics) attached to a small tree such that both microphones protruded beyond the tree trunk at $1.5 \mathrm{~m}$ above the ground. A portable sound production system (Pyramid PB444X 400W amplifier; digital timer, Diehl 884 series; 12V 10 AH lead-acid battery, and a Raspberry Pi computer) was also placed in the center of the sample area, and four playback speakers $(25 \mathrm{~W}, 0.4-6 \mathrm{kHz}$ frequency range; Pyle PHSP6K) were placed $1.5 \mathrm{~m}$ from the ground at $25 \mathrm{~m}$ from the center in each cardinal direction. Once a location was selected for inclusion in the study, two days of pre-experimental acoustic recordings were collected to establish baseline vocal rates. Recording began at sunrise, and continued for 70 minutes.

After collection of baseline data, songbird vocalizations were recorded for three additional mornings. Playback of road noise was introduced in experimental sites during this period. Playback consisted of a 90-minute presentation of pre-recorded road noise. The noise stimulus was a repeated $1 \mathrm{~s}$ segment of road noise cut from a high-quality recording collected previously near a high use highway with continuous traffic moving at approximately $65 \mathrm{mph}$. The $1 \mathrm{~s}$ stimulus was free from abnormal anthropic (e.g., tractor-trailer or motorcycles) or biotic sounds (e.g., birdsong). Playback amplitude was adjusted to ensure $65 \pm 2 \mathrm{dBA}$ at the center of the site (1 min Leq; Casella 633 Sound level meter). To 
Table 1. Nineteen songbird species used for manual counts of vocalizations in control conditions and during noise gaps within noise playback.

\begin{tabular}{|c|c|}
\hline Common name & Scientific name \\
\hline Acadian flycatcher & Empidonax virescens \\
\hline American robin & Turdus migratorius \\
\hline Black-throated green warbler & Dendroica virens \\
\hline Blue-winged warbler & Vermivora pinus \\
\hline Chipping sparrow & Spizella passerina \\
\hline Common yellowthroat & Geothlypis trichas \\
\hline Eastern towhee & Pipilo erythrophthalmus \\
\hline Eastern wood-pewee & Contopus virens \\
\hline Field sparrow & Spizella pusilla \\
\hline Gray catbird & Dumetella carolinensis \\
\hline Great crested flycatcher & Myiarchus crinitus \\
\hline Northern cardinal & Cardinalis cardinalis \\
\hline Ovenbird & Seiurus aurocapilla \\
\hline Red-bellied woodpecker & Melanerpes carolinus \\
\hline Red-eyed vireo & Vireo olivaceus \\
\hline Song sparrow & Melospiza melodia \\
\hline Tufted titmouse & Baeolophus bicolor \\
\hline Wood thrush & Hylocichla mustelina \\
\hline Yellow warbler & Dendroica petechia \\
\hline
\end{tabular}

achieve this, the amplitude at each speaker was $90 \pm 2 \mathrm{dBA}$. Although playback speakers were directional, sound levels remained $>65 \mathrm{dBA}$ for at least $10 \mathrm{~m}$ behind the speaker location. This extended noise exposure over the entire $35 \mathrm{~m}$ radius of the sampling area. Noise playback began 30 minutes prior to sunrise, and increased slowly in amplitude (linear ramp, Audacity 2.02) to reduce the likelihood that birds would avoid the area due to the novelty of the stimulus (Figure 2). Full noise levels were achieved by sunrise. Noise playback continued for one hour, but contained three one-minute and three five-minute quiet gaps. To avoid startling nearby songbirds, a five second ramp was applied to the offset and onset of all noise events.

\section{Point counts}

Since changes in observed vocalization rates may be due to differences in presence rather than behavior, we assessed site fidelity during the playback period. We conducted daily point counts at all sites 
Day 1 - 3: Control Condition and Pre-playback Period

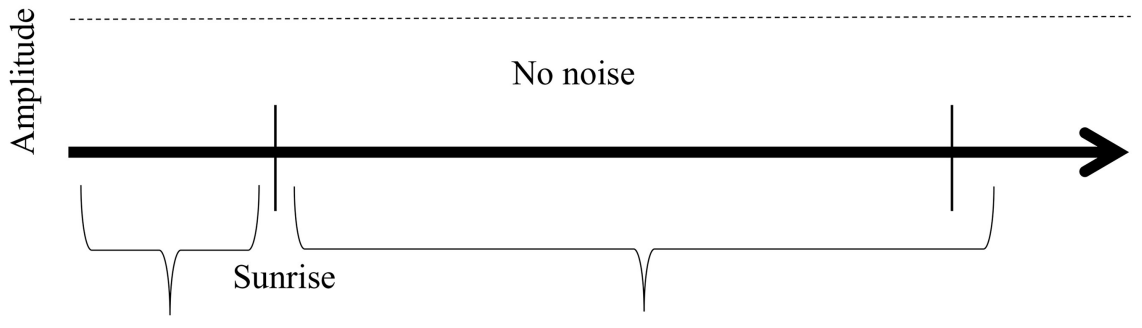

30 minutes: pre-record $\quad 70$ minutes: recording

Day 1 - 3: Experimental Condition

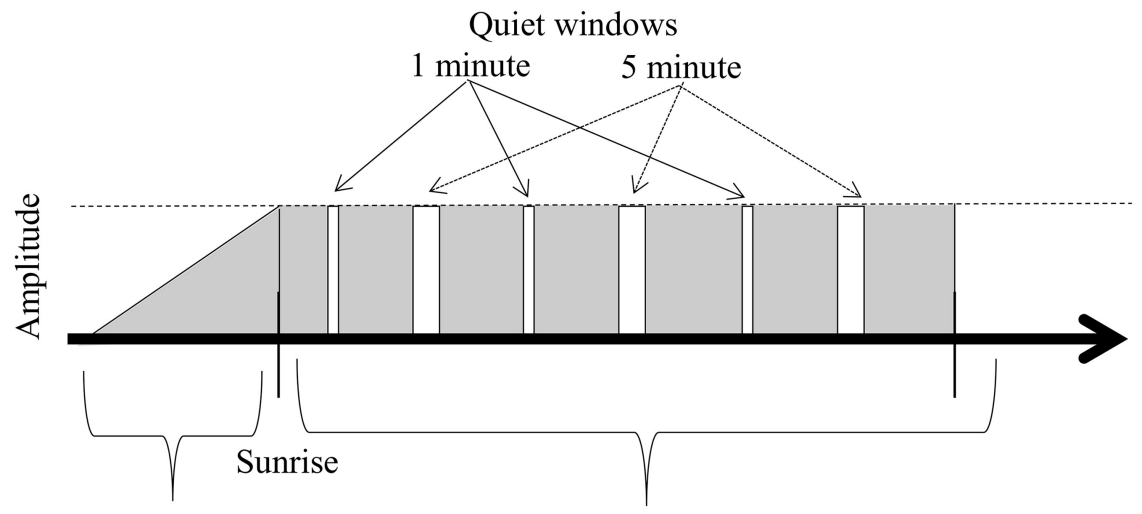

30 minutes: noise ramp 70 minutes: noise playback and recording

Figure 2. Noise playback and acoustic recording schedule in control and experimental sites.

Pre-playback treatments in all sites mirrored the control condition. One and five minute quiet windows were distributed equally within noise playback. Songs counted during one minute windows were also assessed during the same time period from control sites.

immediately following the playback period in both experimental and control treatments. Ten minute point counts were conducted between cessation of noise playback and 1000 hours. Each focal species was identified by site or sound within a $100 \mathrm{~m}$ radius (Bibby et al., 1992). Our point count radius was larger than the recording area for two reasons. First, birds holding territories within our recording area are likely to move beyond this region regularly without abandoning the area. Second, human observers are not highly adept at placing birds accurately within a narrower radius (Simons et al., 2007). Because detection rates decrease with distance it is likely that most surveyed birds were utilizing noise-affected areas regularly.

\section{Analysis}

We used automated and manual techniques to assess whether vocal rates of a songbird community or particular species were altered during noise playback. Automated techniques included the bioacoustic index (min frequency $=2 \mathrm{kHz}$, max frequency $=10 \mathrm{kHz}, \mathrm{ft}=512$; Boelman et al., 2007) and the acoustic complexity index $(\mathrm{ACI}$; cluster size $=1$, $\max$ frequency $=10 \mathrm{kHz}, \mathrm{fft}=512$, units = seconds; Pieretti et al., 2011). The bioacoustic index is a measure of the area under the curve for all frequency 
bands that exceeds a set $\mathrm{dB}$ below the maximum $(-35 \mathrm{~dB}$ in this case). This index was included as a measure of total vocal output. The ACI is a measure of variability in sound output over time and was included as an estimate of the chorus complexity since each additional species adds a uniquely varying sound signature. If noise playback increased vocal output as we hypothesized, we predicted that the bioacoustic index would be higher in gaps during noise playback. However, if only a subset of species dominated vocal production, we predicted that the ACI would decrease with noise playback. We calculated both indices for the first minute after noise offset in the one and five minute gaps during noise playback, and immediately following the completion of noise playback (R Core Team, 2013; package soundecology). The one-minute time period was selected because it encompassed the maximum duration that was available in all replicates. In addition, we manually counted all vocalizations from our 19 focal species in all one-minute noise gaps. Counts and indices were also assessed in gaps during the corresponding times in control and baseline recordings.

To increase the likelihood that we visually detected only vocalizations that were produced by individuals within our experimental plot, we played back pre-recorded yellow warbler (Setophaga petechia), wood thrush (Hylocichla mustelina), and red-eyed vireo (Vireo olivaceus) songs (common species at our sites) at the edge of our $35 \mathrm{~m}$ radius $(80 \pm 2 \mathrm{dBA}$ at $1 \mathrm{~m})$ during the setup of 8 sites. These songs were re-recorded with SM1 units at the center of each site. Recorded songs were viewed in Audacity 2.02 on a non-normalized fast Fourier transform spectrogram (fft). Spectral settings were adjusted such that re-recorded songs fell near the edge of visibility (Hanning, window size $=2,048$, frequency range $=1-10 \mathrm{kHz}$, range $=75 \mathrm{~dB}$, gain $=20$ ). Thus, vocalizations produced beyond the range of our plots were generally not visible to the observer on spectral displays. These standardized settings were used for the duration of the experiment, and all visible vocalizations within one-minute windows were counted. Only songs were identified for 18 species. Kwirr calls were counted for the red-bellied woodpecker because this species does not produce song, but its call is associated with breeding activity (Kilham, 1983). Automated and manual analyses were restricted to replicates free from rain or wind ( $<3$ on the Beaufort scale).

Acoustic indices and vocalization rates were compared via general linear mixed models (glmer, package lme4). The global model for both indices included treatment (baseline/control/noise) and date (Julian). For manual counts, the global model also included species and gap order (1-3). Julian date and gap order were included to account for predictable seasonal and daily declines in vocalization rates. Site was included as a random factor in all models to account for the lack of independence between repeated samples at each site. Reduced models were compared to the global model to determine whether removing the treatment or species (where applicable) term significantly improved the model fit (compared via Analysis of variance). We also ran species-specific models which contained the same terms (except "species") and significance tests as the community model. In models where the treatment term was retained, we ran pairwise comparisons (glht, package multcomp) to determine which treatments differed. The effect of noise on indices and vocalization rates was considered significant when the output during quiet gaps within noise playback differed significantly from both the baseline and control condition, and the direction (+ or - ) of the effect was the same in both cases. These qualifications provided a conservative test of noise-associated changes in vocalization rates because it required the presence of a robust and consistent pattern.

To determine whether birds remained onsite sites during experimentation we ran a multivariate analysis of variance (MANOVA) test for differences in abundance between treatments, day (numbered $1-5 ; 1-2=$ baseline, $3-5=$ treatment), and the interaction between the two terms. Specific playback days were retained to examine whether abundance became increasingly disparate as noise playback continued. Each species $(\mathrm{N}=19)$ was included as a dependent variable. Values of $p<0.05$ were considered to be significant for all tests.

\section{Results}

The best model retained the treatment term for the bioacoustic index $\left(\chi_{2}^{2}=21.55, p=0.039\right.$; details for all models can be found in Supplementary Material S.1). Although output during noise playback 
was significantly higher than baseline ( $x=8.24$ and 8.03 respectively, $z=2.52, p=<0.032)$ it did not differ from the control treatment $(x=8.15, z=0.88, p=0.653)$, and thus, was not considered significant. Acoustic complexity during gaps in noise playback $(x=333.72)$ was lower than either the baseline $(x=348.56)$ or control condition $(x=347.52)$, but the relationship was not significant $\left(\chi_{2}^{2}=2.35, p=0.308\right)$. The community-wide model for vocalization rate retained the treatment $\left(\chi_{2}^{2}=21.55, p=<0.001\right)$ and species $\left(\chi_{18}^{2}=28947.00, p=<0.001\right)$ terms. Vocal rates differed between the baseline and control treatment $(z=4.45, p=<0.001)$ and the noise and control treatment $(z=-3.38, p=0.002)$, but not between noise and baseline $(z=0.96, p=0.605)$. Because noise did not differ from both treatments, we did not consider the impact of noise playback on community vocalization rates to be significant.

The species term was retained in the community model indicating that not all species responded vocally in the same manner (S.1, Table 3). The best individual model for seven species did not retain the treatment term (S.1, Tables 4-21). An additional eight species retained the treatment term, but did not exhibit a consistent, directional pattern of vocal increase or decrease under noise playback. Two species, the chipping sparrow (Spizella passerine $\chi_{2}^{2}=39.29, p=<0.001$, Figure 3a) and field sparrow (Spizella pusilla $\chi_{2}^{2}=30.52, p=<0.001$, Figure $3 \mathrm{~b}$ ), vocalized significantly less during gaps in noise playback than in baseline or control treatments $(58.1 \%$ and $28.1 \%$ reduction from from the mean of both non-noise conditions, respectively). Conversely, two additional species, the gray catbird (Dumetella carolinensis $\chi_{2}^{2}=76.83, p=<0.001$, Figure $3 c$ ) and song sparrow (Melospiza melodia $\chi^{2}{ }_{2}=27.03, p=<0.001$, Figure $3 \mathrm{~d}$ ), vocalized significantly more during gaps in noise playback the in baseline or control treatments $(306.4 \%$ and $188.2 \%$ increase from non-noise conditions, respectively).
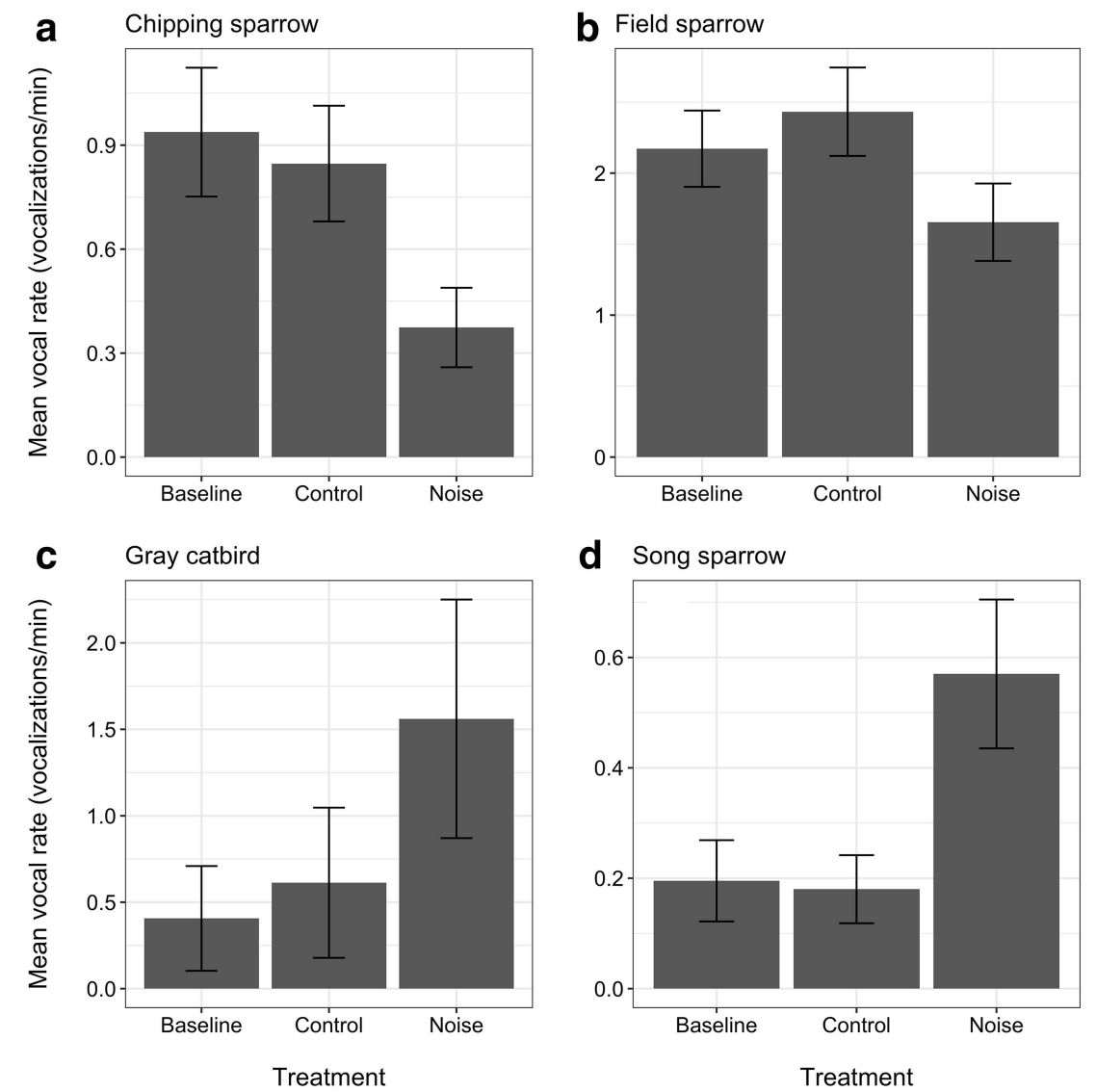

Figure 3. Mean vocalization rates $( \pm S E)$ for four species whose vocal output during gaps in noise playback differed significantly from baseline and control treatments. 
MANOVA analysis of point count data suggests that focal species did not leave the area in response to noise playback. Neither treatment (Wilks' $\lambda F_{19,60}=0.889, p=0.597$ ), day (Wilks' $\lambda F_{76,238}=0.775, p=0.904$ ), nor the interaction between treatment and day (Wilks' $\lambda F_{76,234}=1.078, p=0.330$ ) approached significance.

\section{Discussion}

Support for our prediction that songbirds would vocalize more often during quiet gaps embedded within anthropogenic noise was low, although not entirely absent. Community-wide analysis provided no evidence for significantly altered rates of vocalization in gaps during noise playback. This nonsignificant pattern also held true for the majority of individual species, however, a few significant patterns emerged. Specifically, gray catbirds and song sparrows increased vocal production during noise embedded gaps, while field sparrows and chipping sparrows decreased vocal rates during the same period. Point count data suggests that the community composition was not altered during noise playback, making it unlikely that movement away from the noise source confounded our results. It is also noteworthy that results from the bioacoustic index, which did not decrease with noise playback, and ACI, which did decrease with noise playback, match our manual assessment of vocal output. The similarity in overall output is in keeping with the observation that two species increased vocal output, potentially replacing two other species that decreased output. But the reduce output of the latter two species would be expected to reduce chorus complexity.

A number of biological explanations could account for our generally non-significant results. First, it is conceivable that most songbirds are not capable or willing to make fine-scale temporal adjustments to noise. A physical constraint would be somewhat surprising given the number of species known to shift vocal timing in relation to other biotic sounds (Egnor et al., 2007; Brumm and Zollinger, 2013; Gil et al., 2015). However our results are similar to those of Yang and Slabbekoorn (2014) who found that Eurasian wrens, a species known to temporally shift acoustic output to avoid conspecific vocal overlap, did not temporally shift song to avoid overlap with anthropogenic noise. Perhaps, the social constraints that regulate songbird communication (e.g., Hall et al., 2006; Vehrencamp et al., 2007) prevent fine-scale temporal shifts in vocal production.

The lack of modification in temporal vocal patterns could be due to the recent evolutionary appearance of anthropogenic noise in the soundscape, resulting in an underdeveloped cue-response system (Sih, 2013). It is plausible that temporal shifting could become more common with increased noise exposure as a result of learning or selection for individuals that utilize noise gaps (Swaddle et al., 2015). It should also be noted that the current study was short-term, and took place within a community of songbirds that were naïve to anthropogenic noise. If temporal shifting is a learned response, individuals that experience chronic noise interference may yet shift vocal production to utilize noise gaps. Novelty may also impact singing behavior. Specifically, birds may be less likely to vocalize due to a neophobic response to noise on the landscape. However, most species in the current study did not reduce vocal rates, suggesting that novelty effects were minimal. Longer-term studies are needed to assess these longer-term responses. Nonetheless, the lack of evidence for immediate behavioral plasticity in this trait differs from what has been found in other traits used to communicate in noise, such as frequency shifting (e.g., Gross et al., 2010).

Another possible explanation for the lack of temporal shifts is that noise tolerant species possess plasticity in other traits that allows them to sufficiently reduce overlap with anthropogenic noise. Dowling et al. (2012) simultaneously studied the effects of noise on four of the most abundant urban species utilized in our study (American robin, Turdus migratorius; Northern cardinal, Cardinalis cardinalis; song sparrow, and gray catbird). All species increased song frequency (pitch) as noise levels increased. Further, urban European robins (Fuller et al., 2007) and European blackbirds (Turdus merula, Nordt and Klenke, 2013) shift their dawn chorus to pre-dawn hours to avoid noise overlap. When studied in relation to urban lighting, the American robin also demonstrated the ability to shift towards pre-dawn song production (Miller, 2006). It is also possible that birds utilize microhabitats that are less impacted by noise, or move closer to conspecifics to facilitate communication. Perhaps 
these spectral, spatial and larger scale temporal shifts are sufficient for successful communication in species commonly found in noisy areas. Although testing these alternative mechanisms is beyond the scope of the current study, two of our species that altered temporal patterns also shift vocal frequencies in noise (i.e., song sparrow and gray catbird). This anecdotal evidence suggests that frequency shifting may not preclude the use of other mechanisms for enhancing vocal communication in noise.

Four species diverged from the generally non-significant patterns. Song sparrows and gray catbirds vocalized more often during noise gaps, a behavioral shift that could facilitate communication within anthropogenic noise by utilizing limited acoustic space. The song sparrow and gray catbird are two of the more abundant species reported in developed counties within the study region (observed on $48.6 \%$ and $47.3 \%$ of ebird lists submitted May-June in all years for Wayne, Kent, and Kalamazoo counties). Rapid temporal shifts in vocalization rates combined with frequency shifting (Wood and Yezerinac, 2006; Dowling et al., 2012) may underlie the urban success observed in these species. The field sparrow and chipping sparrow are less common in the region's developed counties $(11.6 \%$ and $29.7 \%$ of lists respectively). Their reduced vocalization rate could be a direct response to anthropogenic noise or result of subordinate status when interacting with heterospecifics (Walkinshaw, 1968; Fretwell and Lucas, 1969). For example, increased vocalization by song sparrows may have precluded the subordinate field sparrow from utilizing available acoustic space. This type of interaction has been noted previously in an assembly of anuran species (Sun and Narins, 2005). Under this scenario, anthropogenic noise may have a cascading effect on the songbird community (e.g., Francis et al., 2009).

In summary, temporal patterns of vocal output by a songbird community were generally unaffected by short-term noise playback, suggesting that rapid temporal shifting to maximize communication in noise is not a common avian response. Temporal shifting to avoid noise overlap may be limited by social constraints, and longer term noise exposure may facilitate learning or select for individuals that utilize noise gaps. However, immediate behavioral plasticity is uncommon. Only 4 of 19 species vocalized at different rates within gaps embedded in noise. Increased rates in song sparrows and gray catbirds may facilitate successful communication in noise-affected areas, and warrants further investigation. Conversely, decreased vocal rates in field and chipping sparrows demonstrates the potentially adverse impacts of anthropogenic noise on communication, either directly or through acoustic competition with heterospecifics for limited acoustic space. For most species, the inability to shift vocalizations into quiet gaps eliminates one mechanism for communicating under elevated anthropogenic noise. This may help to explain why a reduced number of species typically inhabit noisy areas.

\section{Supporting material}

\section{S1. Supplementary Information. (HTML)}

\section{Acknowledgements}

Data collection was funded and facilitated by the Pierce Cedar Creek Institute in Hastings, Michigan. Research was approved by the Calvin College Institutional Animal Care and Use Advisory Committee (BR2013-02). We would like to thank R Keys for access to previous point count data and H Brown for contributing to manuscript preparation. Special thanks also go to the Pierce Cedar Creek staff who helped us move equipment between sites throughout the field season. Thanks to S Cowell, L DeJong, and T Nguyen for assistance in data analysis. Finally, we are indebted to the editor and two anonymous reviewers whose suggestions greatly improved the manuscript.

\section{Funding sources}

Pierce Cedar Creek Institute. 


\section{Competing interests}

Darren S Proppe and Emily Finch declare that they have no conflict of interest.

\section{References}

Arroyo-Sollis A., Castillo J. M., Figueroa E., Lopez-Sanchez J. L., and Slabbekoorn H. (2013). Experimental evidence for an impact of anthropogenic noise on dawn chorus timing in urban birds. Journal of Avian Biology. 44 (3): 288-296. https://doi. org/10.1111/j.1600-048X.2012.05796.x.

Bayne E. M., Habib L., and Boutin S. (2008). Impacts of chronic anthropogenic noise from energy-sector activity on abundance of songbirds in the boreal forest. Conservation Biology. 22 (5): 1186-1193. https://doi.org/10.1111/j.15231739.2008.00973.x.

Bibby C. J., Burgess N. D., and Hill D. A. (1992). Bird Census Techniques. London: Academic Press.

Boelman N. T., Asner G. P., Hart P. J., and Martin R. E. (2007). Multi-trophic invasion resistance in Hawaii: Bioacoustics, field surveys, and airborne remote sensing. Ecological Applications. 17 (8): 2137-2144. https://doi.org/10.1890/07-0004.1.

Brumm H. (2004). The impact of environmental noise on song amplitude in a territorial bird. Journal of Animal Ecology. 73 (3): 434-440. https://doi.org/10.1111/j.0021-8790.2004.00814.x.

Brumm H. (2006). Signalling through acoustic windows: Nightingales avoid interspecific competition by short-term adjustment of song timing. Journal of Comparative Physiology A. 192 (12): 1279-1285. https://doi.org/10.1007/s00359006-0158-x.

Brumm H. and Zollinger S. A. (2013). Avian vocal production in noise. In: Animal Communication in Noise (Animal Signals and Communication, vol 2), edited by Brumm H. Berlin, Heidelberg: Springer. 187-227.

Dowling J. L., Luther D. A., and Marra P. P. (2012). Comparative effects of urban development and anthropogenic noise on bird songs. Behavioral Ecology. 23 (1): 201-209. https://doi.org/10.1093/beheco/arr176.

Egnor S. E., Wickelgren J. G., and Hauser M. D. (2007). Tracking silence: Adjusting vocal production to avoid acoustic interference. Journal of Comparative Physiology A. 193 (4): 477-483. https://doi.org/10.1007/s00359-006-0205-7.

Fitzsimmons L. P., Foote J. R., Ratcliffe L. M., and Mennill D. J. (2008). Frequency matching, overlapping and movement behaviour in diurnal countersinging interactions of black-capped chickadees. Animal Behaviour. 75 (6): 1913-1920. https:// doi.org/10.1016/j.anbehav.2007.11.006.

Francis C. D. and Barber J. R. (2013). A framework for understanding noise impacts on wildlife: An urgent conservation priority. Frontiers in Ecology and the Environment. 11 (6): 305-313. https://doi.org/10.1890/120183.

Francis C. D., Ortega C. P., and Cruz A. (2009). Noise pollution changes avian communities and species interactions. Current biology. 19 (16): 1415-1419. https://doi.org/10.1016/j.cub.2009.06.052.

Fretwell S. D. and Lucas H. L. (1969). On territorial behavior and other factors influencing habitat distribution of birds. Acta Biotheoretica. 19 (1): 16-36. https://doi.org/10.1007/BF01601953.

Fuller R. A., Warren P. H., and Gaston K. J. (2007). Daytime noise predicts nocturnal singing in urban robins. Biology Letters. 3 (4): 368-370. https://doi.org/10.1098/rsbl.2007.0134.

Gil D., Honarmand M., Pascual J., Pérez-Mena E., and Macías Garcia C. (2015). Birds living near airports advance their dawn chorus and reduce overlap with aircraft noise. Behavioral Ecology. 26 (2): 435-443. https://doi.org/10.1093/beheco/ aru207.

Greenfield M. D. (1994). Synchronous and alternating choruses in insects and anurans: Common mechanisms and diverse functions. Integrative and Comparative Biology. 34 (6): 605-615. https://doi.org/10.1093/icb/34.6.605.

Gross K., Pasinelli G., and Kunc H. (2010). Behavioral plasticity allows short term adjustment to a novel environment. The American Naturalist. 176 (4): 456-464. https://doi.org/10.1086/655428.

Halfwerk W., Holleman L. J. M., Lessells C. M., and Slabbekoorn H. (2011). Negative impact of traffic noise on avian reproductive success. Journal of Applied Ecology. 48 (1): 210-219. https://doi.org/10.1111/j.1365-2664.2010.01914.x.

Hall M. L., Illes A., and Vehrencamp S. L. (2006). Overlapping signals in banded wrens: Long-term effects of prior experience on males and females. Behavioral Ecology. 17 (2): 260-269. https://doi.org/10.1093/beheco/arj022.

Hart P. J., Hall R., Ray W., Beck A., and Zook J. (2015). Cicadas impact bird communication in a noisy tropical rainforest. Behavioral Ecology. 26 (3): 839-842. https://doi.org/10.1093/beheco/arv018.

Hu Y. and Cardoso G. C. (2009). Are birds that vocalize at higher frequencies preadapted to inhabit noisy areas? Behavioral Ecology. 20 (6): 1268-1273. https://doi.org/10.1093/beheco/arp131.

Kerner B. S. and Rehborn H. (1996). Experimental properties of complexity in traffic flow. Physical Review E. 53 (5): R4275-R4278. https://doi.org/10.1103/PhysRevE.53.R4275. 
Kilham L. (1983). Life history studies of woodpeckers of eastern North America. Cambridge, MA: Nuttall Ornithological Club, Harvard University.

McClure C. J. W., Ware H. E., Carlisle J., Kaltenecker G., and Barber J. R. (2013). An experimental investigation into the effects of traffic noise on distributions of birds: Avoiding the phantom road. Proceedings of the Royal Society B. 280 (1773): 20132290. https://doi.org/10.1098/rspb.2013.2290.

Mennitt D., Fristrup K. M., Sherrill K., and Nelson L. (2013). Mapping sound pressure levels on continental scales using a geospatial sound model. Proceedings of Inter-Noise. 1-11.

Miller M. W. (2006). Apparent effects of light pollution on singing behavior of American robins. The Condor. 108 (1): 130 139. https://doi.org/10.1650/0010-5422(2006)108[0130:AEOLPO]2.0.CO;2.

Naguib M. and Mennill D. J. (2010). The signal value of birdsong: Empirical evidence suggests song overlapping is a signal. Animal Behaviour. 80 (3): e11-e15. https://doi.org/10.1016/j.anbehav.2010.06.001.

Nemeth E. and Brumm H. (2010). Birds and anthropogenic noise: Are urban songs adaptive? American Naturalist. 176 (4): 465-475. https://doi.org/10.1086/656275.

Nordt A. and Klenke R. (2013). Sleepless in town: Drivers of the temporal shift in dawn song in urban European blackbirds. PLoS ONE. 8 (8): e71476. https://doi.org/10.1371/journal.pone.0071476.

Pieretti N., Farina A., and Morri D. (2011). A new methodology to infer the singing activity of an avian community: The Acoustic Complexity Index (ACI). Ecological Indicators. 11 (3): 868-873. https://doi.org/10.1016/j.ecolind.2010.11.005.

R Core Team (2013). R: A language and environment for statistical computing. Vienna, Austria: R Foundation for Statistical Computing. http://www.R-project.org/.

Reijnen R. and Foppen R. (1995). The effects of car traffic on breeding bird populations in woodland 4. Influence of population-size on the reduction of density close to a highway. Journal of Applied Ecology. 32 (3): 481-491. https://doi.org/ $10.2307 / 2404646$

Rheindt F. E. (2003). The impact of roads on birds: Does song frequency play a role in determining susceptibility to noise pollution? Journal Fur Ornithologie. 144 (3): 295-306. https://doi.org/10.1007/BF02465629.

Schneider C., Hodges K., Fischer J., and Hammerschmidt K. (2008). Acoustic niches of siberut primates. International Journal of Primatology. 29 (3): 601-613. https://doi.org/10.1007/s10764-007-9181-1.

Schwartz J. J. and Bee M. A. (2013). Anuran acoustic signal production in noisy environments. In: Animal Communication in Noise (Animal Signals and Communication, vol 2), edited by Brumm H. Berlin, Heidelberg: Springer. 91-132.

Sih A. (2013). Understanding variation in behavioural responses to human-induced rapid environmental change: A conceptual overview. Animal Behaviour. 85 (5): 1077-1088. https://doi.org/10.1016/j.anbehav.2013.02.017.

Simons T. R., Alldredge M. W., Pollock K. H., and Wettroth J. M. (2007). Experimental analysis of the auditory detection process on avian point counts. The Auk. 124 (3): 986-999. https://doi.org/10.1642/0004-8038(2007)124[986:EAOTAD] 2.0.CO;2.

Slabbekoorn H. and Peet M. (2003). Ecology: Birds sing at a higher pitch in urban noise - Great tits hit the high notes to ensure that their mating calls are heard above the city's din. Nature. 424: 267-267. https://doi.org/10.1038/424267a.

Slabbekoorn H. and Ripmeester E. A. P. (2008). Birdsong and anthropogenic noise: Implications and applications for conservation. Molecular Ecology. 17 (1): 72-83. https://doi.org/10.1111/j.1365-294X.2007.03487.x.

Sun J. W. and Narins P. M. (2005). Anthropogenic sounds differentially affect amphibian call rate. Biological conservation. 121 (3): 419-427. https://doi.org/10.1016/j.biocon.2004.05.017.

Swaddle J. P. and Page L. C. (2007). High levels of environmental noise erode pair preferences in zebra finches: Implications for noise pollution. Animal Behaviour. 74 (3): 363-368. https://doi.org/10.1016/j.anbehav.2007.01.004.

Swaddle J. P., Francis C. D., Barber J. R., Cooper C. B., Kyba C. C. M., et al. (2015). A framework to assess evolutionary responses to anthropogenic light and sound. Trends in Ecology and Evolution. 30 (9): 550-560. https://doi.org/10.1016/j. tree.2015.06.009.

Vehrencamp S. L., Hall M. L., Bohman E. R., Depeine C. D., and Dalziell A. H. (2007). Song matching, overlapping, and switching in the banded wren: The sender's perspective. Behavioral Ecology. 18 (5): 849-859. https://doi.org/10.1093/ beheco/arm054.

Walkinshaw L. H. (1968). Eastern field sparrow. Life Histories of North American Cardinals, Grosbeaks, Buntings, Towhees, Finches, Sparrows, and Allies. New York: Dover Publications, Inc. 1217-1235.

Wood W. E. and Yezerinac S. M. (2006). Song sparrow (Melospiza melodia) song varies with urban noise. The Auk. 123 (3): 650-659. https://doi.org/10.1642/0004-8038(2006)123[650:SSMMSV]2.0.CO;2.

Yang X. J. and Slabbekoorn H. (2014). Timing vocal behavior: Lack of temporal overlap avoidance to fluctuating noise levels in singing Eurasian wrens. Behavioural processes. 108: 131-137. https://doi.org/10.1016/j.beproc.2014.10.002. 